\title{
Evolution of boldness and exploratory behavior in giant mice from Gough Island
}

\author{
Jered A. Stratton ${ }^{1}$ (D) Mark J. Nolte $^{1} \cdot$ Bret A. Payseur $^{1}$ \\ Received: 6 October 2020 / Revised: 26 February 2021 / Accepted: 4 March 2021 / Published online: 15 March 2021 \\ (C) The Author(s) 2021
}

\begin{abstract}
Island populations are hallmarks of extreme phenotypic evolution. Radical changes in resource availability and predation risk accompanying island colonization drive changes in behavior, which Darwin likened to tameness in domesticated animals. Although many examples of animal boldness are found on islands, the heritability of observed behaviors, a requirement for evolution, remains largely unknown. To fill this gap, we profiled anxiety and exploration in island and mainland inbred strains of house mice raised in a common laboratory environment. The island strain was descended from mice on Gough Island, the largest wild house mice on record. Experiments utilizing open environments across two ages showed that Gough Island mice are bolder and more exploratory, even when a shelter is provided. Concurrently, Gough Island mice retain an avoidance response to predator urine. F1 offspring from crosses between these two strains behave more similarly to the mainland strain for most traits, suggesting recessive mutations contributed to behavioral evolution on the island. Our results provide a rare example of novel, inherited behaviors in an island population and demonstrate that behavioral evolution can be specific to different forms of perceived danger. Our discoveries pave the way for a genetic understanding of how island populations evolve unusual behaviors.
\end{abstract}

\section{Significance}

Organisms on islands are known to behave differently from mainland organisms. An absence of predators and a different set of natural resources are expected to make island organisms less anxious and more exploratory. We raised two groups of house mice, one from Gough Island in the South Atlantic and one from the mainland Eastern USA, in the same laboratory environment to see if behavioral differences between the two groups are heritable. Mice from both groups were placed in novel enclosures that are known to cause anxiety in rodents. We found that mice from the island are bolder and more exploratory in these enclosures but avoid predator odors in the same way as mainland mice. Our results show that boldness and exploration can evolve after island colonization.

Keywords Island syndrome $\cdot$ House mice $\cdot$ Anxiety $\cdot$ Island evolution $\cdot$ Island tameness $\cdot$ Behavior

\section{Introduction}

Organisms that colonize islands experience unique environmental challenges that require novel solutions (Losos and Ricklefs 2009). New kinds and distributions of resources on islands can select for new foraging strategies (Williamson

Communicated by E. Korpimäki

Jered A. Stratton

jstratton2@wisc.edu

1 Laboratory of Genetics, University of Wisconsin - Madison, Madison, WI 53706, USA
1981; Grant 1998, 1999). For many island colonizers, a loss of predators alleviates the need for behavioral or morphological defenses (Williamson 1981; Blumstein and Daniel 2005; Dmitriew 2011). If resources are difficult to acquire and predatory risk is absent, the optimal foraging-risk ratio is highly skewed, favoring exploration and boldness (Brown and Kotler 2004; Creel and Christianson 2008; Elliott et al. 2017). Island populations, therefore, provide opportunities to test hypotheses about the evolution of behavior in novel environments.

Populations that spread to islands often display behavioral changes. Many populations lose anti-predator behaviors (Blumstein and Daniel 2005). Some island inhabitants are more easily approached by humans, a phenomenon Darwin called "island tameness" (Darwin 1840; Cooper et al. 2014). 
In some island rodents, territoriality and conspecific aggression are reduced compared to mainland populations (Halpin 1981; Baier and Hoekstra 2019). Behavioral responses to island environments sometimes occur in the context of other phenotypic shifts. New behaviors are often accompanied by transitions in life history and morphology (Foster 1964; Halpin 1981; Berry 1992) in a pattern referred to as the "island syndrome" (Adler and Levins 1994).

Although behavior is suspected to be an important component of adaptation to island conditions, the question of whether island populations harbor heritable changes in behavior has rarely been answered (Jolly et al. 2018; Baier and Hoekstra 2019). Demonstrating that behavior has evolved on islands requires evidence of genetic change in behavioral traits.

A promising organismal system for testing hypotheses about behavioral evolution in response to island environments is found on Gough Island, a remote volcanic island in the middle of the South Atlantic Ocean. Despite the remote location of Gough Island, over $2700 \mathrm{mi}$ from the nearest mainland, house mice (Mus musculus domesticus) colonized the island, probably via sealing ships from Western Europe a few hundred generations ago (Verrill 1895; Wace 1961; Gray et al. 2014). In a remarkable phenotypic transformation, these mice evolved a body size twice that of their mainland counterparts (Rowe-Rowe and Crafford 1992; Jones et al. 2003). Laboratory-born offspring of Gough Island mice (hereafter "GI mice") maintain their unusual size, confirming that this morphological distinction has a genetic basis (Gray et al. 2015; Parmenter et al. 2016). On Gough Island, mice live without the predators and without the human commensals they commonly exploit for food and shelter on the mainland (Rowe-Rowe and Crafford 1992; Phifer-Rixey and Nachman 2015). The diet of GI mice is highly variable and seasonal, with invertebrates (mainly earthworms) and seeds being the most stable food source (Jones et al. 2003). During the winter season, GI mice predate on endangered seabird populations that use the island as a nesting ground, leading to the deaths of an estimated 2 million chicks and/or eggs per year (Caravaggi et al. 2019). The combination of increased body size, novel consumption of birds, loss of predatory danger, and removal of human commensals predicts the evolution of increased exploration and boldness in GI mice. Because GI mice are western European house mice (Mus musculus domesticus), the same subspecies as the laboratory mouse (Gray et al. 2014), established methods in biomedical research can be applied to profile behavioral evolution.

In this article, we use GI mice to examine recent behavioral evolution on an island. By exposing juvenile and adult mice to novel environments with different levels of perceived risk, we uncovered multiple lines of evidence that GI mice are bolder (i.e., less anxious) and more exploratory than mice from a mainland reference strain. The detection of these differences among inbred strains raised in a common environment demonstrates that they are inherited. Our findings indicate that GI mice evolved enhanced boldness and exploration (evidenced by the distance traveled during a behavioral test) over a short timescale and in concert with other substantial phenotypic changes. This work lays the foundation for identifying the genetic changes responsible for behavioral evolution in organisms that colonize islands.

\section{Materials and methods}

\section{Mouse strains and husbandry}

Inbred strains of GI mice and mainland mice were used throughout this study. In 2009, GI mice were live-caught and shipped to the University of Wisconsin School of Veterinary Medicine Charmany Instructional Facility, where a breeding colony was established (Gray et al. 2015). GI mice for this study belonged to a strain maintained for 21-23 generations of brother-sister mating. At this stage of inbreeding, we expect most of the genome to be homozygous, allowing us to treat individual mice as replicates of the same genetic background. Mainland mice belonged to the WSB/EiJ inbred strain founded from breeding pairs caught in Maryland (purchased from the Jackson Laboratory, Bar Harbor, ME) and were maintained in the same colony as GI mice for the same time period. GI mice and house mice from the eastern coast of North America are likely descended from Western Europe (Gray et al. 2014; Phifer-Rixey et al. 2018), though the geographic locations of source populations are unknown. F1s were generated by crossing mice from the GI strain and the mainland strain in both maternal directions. All mice were housed in micro-isolator cages with corn cob substrate (1/8th inch; The Andersons Lab Bedding), with ad libitum access to food (Envigo 2020X Teklad Global Diet) and water. Breeders were provided with a higher fat chow (Envigo 2019 Teklad Global Diet) and a red mouse igloo (Bio Serv). All cages were provided with nesting material and irradiated sunflower seeds (Envigo). Cage changes occurred every 6-8 days or, in the case of a new litter, 10 days after parturition. The colony was kept in a temperature-controlled room $\left(20-23^{\circ} \mathrm{C}\right)$ under a 12 $\mathrm{h}$ light/dark cycle.

Mice used for behavioral testing were weaned 20-21 days after parturition and housed with one littermate of the same sex to reduce behavioral effects of within-cage hierarchies (Horii et al. 2017). All mice were weighed to the nearest tenth of a gram during cage changeouts and after the last behavioral assay (i.e., weekly from ages 4-10 weeks old \pm 1 day).

\section{Behavioral assays}

All behavioral assays were conducted in a room separate from the main colony. Each subject was tested four times 
with the following regimen (see Fig. 1a): open field (4 and 8 weeks old \pm 1 day), light/dark ( 9 weeks old \pm 1 day), and predator cue ( 10 weeks old \pm 1 day). All tests were conducted during the light phase of the light/dark cycle under white, fluorescent light. Females were scored for stage of estrous cycle according to Caligioni (2009) on the same day as testing, beginning with the second open field test. Twelve females (all from the mainland strain) were in estrous the same day as testing. These animals fell within the range of values for each trait measured in that strain and were included in the final analysis. The order of subjects tested within litters each day was randomized. Each test began by bringing the subjects' cage into the room for a 30-min acclimation period. The experimenter remained in the room out of sight of the subjects throughout the acclimation and testing periods except for transfer to and from the arena. The relevant arena for each test (see Fig. 1b-d for examples) was placed in the center of the room next to a movable cart where a computer and video recording hardware were located. The arena was cleaned with $70 \%$ ethanol after each test and at least $5 \mathrm{~min}$ was allowed for the ethanol to evaporate before testing a new subject. For the light/dark test the floor panels were removed and shaken to evaporate the ethanol instead of using a 5-min waiting period. All tests were video recorded using Debut Video Capture Software v 5.33 at default settings with Focus set to 0. A Logitech HD Pro Webcam C920 was positioned directly above the center of the arena.
Two videos were taken before each test to assist in video analysis: an "empty" video containing a short recording of the empty arena and a calibration video containing a short recording of the arena with specific positions marked. The "empty" video was used in aligning all images of the test recording. The calibration video was used in defining coordinates of regions of interest and converted pixels to millimeters. Subsequent subsections provide additional details of experimental design for each test.

\section{Open field test}

The open field $(58 \mathrm{~cm} \mathrm{~W} \times 58 \mathrm{~cm} \mathrm{D} \times 58 \mathrm{~cm} \mathrm{H}$; see Fig. $1 \mathrm{~b})$ was constructed from expanded, white PVC (Grainger Industrial Supply). Lighting in the room was set so that the center of the open field measured $300 \pm 5 \mathrm{~lx}$. A calibration video was taken using a poster board on the bottom of the arena with the center and each corner ( $1 \mathrm{in}$. from both edges) marked by circles drawn with black marker. Subjects were initially placed in the center of the arena facing away from the movable cart. The video recording software was started and the subject was allowed to freely explore the arena. After 30 min of uninterrupted exploration, the subject was returned to its home cage and the number of fecal boli in the arena was counted, a commonly used readout of anxiety originally validated in the rat (Hall 1934).

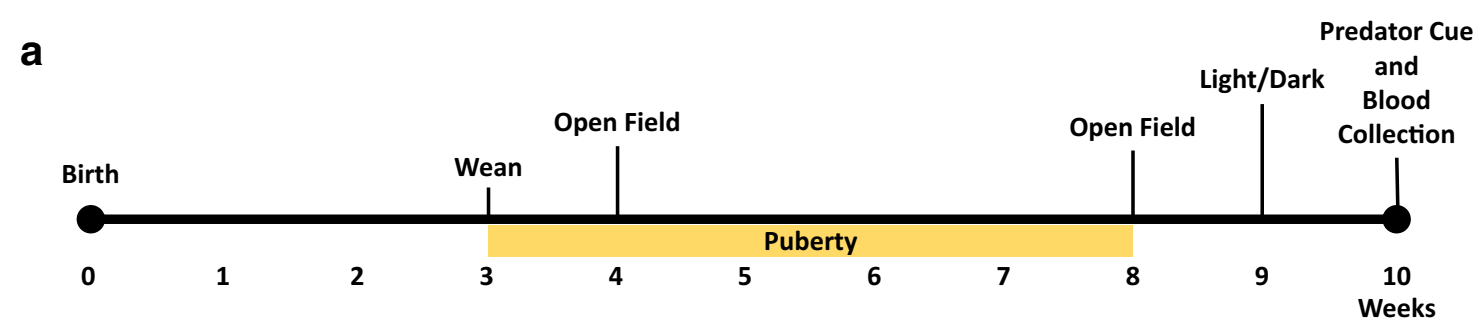

b

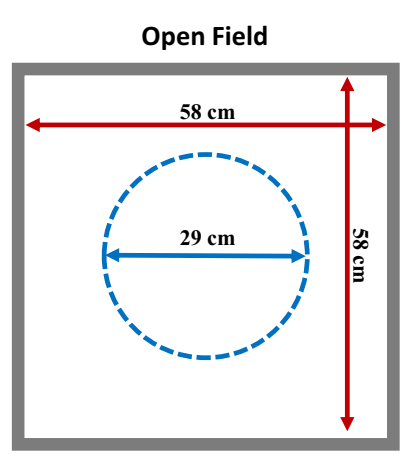

Fig. 1 Schematic of testing design and arenas. a Timeline of a subject mouse's life. b Schematic of the open field arena. The center defined during video analysis is outlined by the dashed circle. c Schematic of the light/dark box. The subject has free access to both equally-sized chambers during the test. Distance to the center threshold is noted by
C

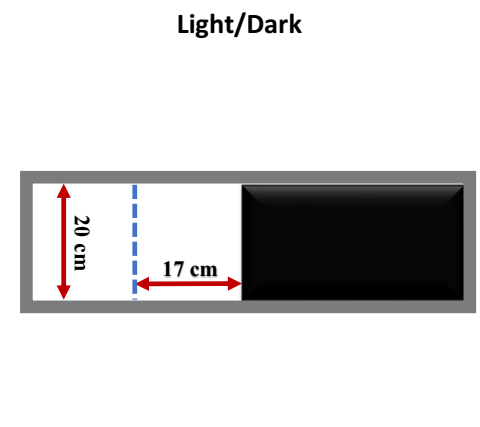

d

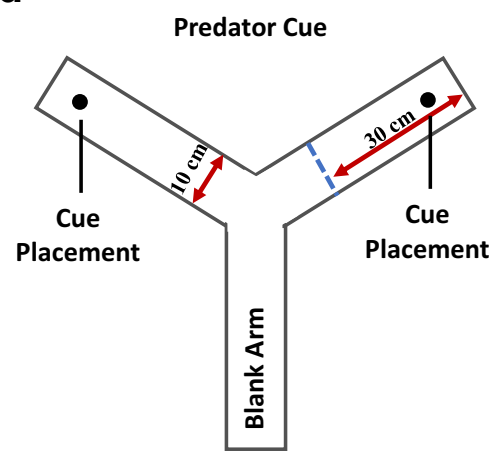

the dashed line. d Schematic of the y-maze used in the predator cue test. Each arm is equally sized and freely accessible. Threshold for each arm defined during video analysis is indicated in the right arm by the dashed line. Locations of the predator and control cues are noted with black dots 


\section{Light/dark test}

A mouse-sized place-preference chamber $(68.6 \mathrm{~cm} \mathrm{~W} \times$ $20.3 \mathrm{~cm} \mathrm{D} \times 38.1 \mathrm{~cm} \mathrm{H}$; San Diego Instruments; Fig. 1c) was used for a light/dark test. One-half of the arena had a black floor and was exteriorly covered with black static cling film. The opposite chamber had a white floor and was interiorly covered with white static cling film (except for the lid to allow video observation). The chamber divider was positioned $4 \mathrm{~cm}$ above the floor to allow free access between both chambers. Lighting was set so that the center of the light chamber measured $300 \pm 5 \mathrm{~lx}$. A calibration video was taken using a separate floor panel placed on top of the floor in the white chamber with the center and each corner (1.27 cm from both edges) marked by circles drawn with black marker. Subjects were initially placed in the center of the light chamber facing the entrance to the dark chamber. The video recording software was started and the subject was allowed to freely explore the arena. After 30 min of uninterrupted exploration, the subject was returned to its home cage and the number of fecal boli in each chamber was counted.

\section{Predator cue test}

A y-maze (San Diego Instruments; each arm $10.16 \mathrm{~cm} \mathrm{~W} \times$ $55.88 \mathrm{~cm} \mathrm{D} \times 50.8 \mathrm{~cm} \mathrm{H}$; Fig. 1d) was used for a predator cue test. Lighting was set so that the center of the $y$-maze measured $300 \pm 5 \mathrm{~lx}$. Two arms were designated as cue arms where either a predator or control cue would be placed. The third arm was designated as the "blank arm." Due to the lighting arrangement of the room, the blank arm was darker $(\sim 150 \mathrm{~lx})$ than the center or cue-containing arms. A calibration video was taken using tightly balled black garbage bags inside the ports of each cue arm and a poster board in the blank arm marking the center and edge of the blank arm with black marker. Subjects were initially placed in the center of the empty y-maze facing the blank arm. The video recording software was started and the subject was allowed to freely explore the arena. After $10 \mathrm{~min}$, the subject was corralled to the end of the blank arm and a barrier was inserted isolating the subject. Fecal boli were then counted and removed. A cotton ball soaked in $4 \mathrm{ml}$ of red fox urine (Minnesota Traplines) was placed in the port of a randomly chosen cue arm as a predator-associated cue. The fox urine came from a 3.785-1 container with pooled samples from an unknown number of individuals. A cotton ball soaked in $4 \mathrm{ml}$ of white-tailed deer urine (Code Blue) was placed in the port of the other cue arm as a non-predator-associated cue. The doe urine came from one of seven separate individuals. The barrier was then removed and the video recording software was started again. After $20 \mathrm{~min}$, the subject was corralled to the end of the blank arm and contained using an insertable barrier. The subject was then anesthetized using a cassette stuffed with isofluranesoaked gauze and transferred to a glass jar along with the cassette for blood collection. The cotton balls were removed from the y-maze and fecal boli were counted. After cleaning the $y$-maze, the cagemate was then tested using the same procedure and cotton balls. Each urine cue was stored at room temperature and concealed from light in rooms separate from the mouse colony and testing room. During the predator cue test, cotton balls soaked in each urine were kept in empty glass microscope slide boxes before being placed in the testing chamber. Experiments were conducted within 7 months after the urine arrived in the lab.

\section{Analysis of videos}

To minimize observer bias, the processing of behavioral videos was blinded with respect to strain. Videos were translated into $\mathrm{x}$ and $\mathrm{y}$ coordinates of the subject for each frame of the video using the following pipeline. First, the raw videos were converted using ffmpeg via the following command:

ffmpeg -i inputFileName.avi -pix_fmt nv12 -f avi vcodec rawvideo convertedFileName.avi

The converted video file was run through an ImageJ script associated with Mousemove (Samson et al. 2015), which we modified to label frames deleted due to inability to maintain the framerate or frames when no mouse was detected. Deleted frames and frames when multiple objects were detected were reincorporated using the position of flanking frames. Calibration videos were run through the same process to obtain positions of known locations in the arena. A small subset of videos had a large number of frames $(>1 \%)$ deleted by erroneously tracking multiple objects. The trajectory files for these videos were manually edited to remove objects that never moved (i.e., not the mouse).

Combined trajectory files were then analyzed to measure a variety of different traits depending on the test (see below). Pixels were translated to mm using known distances between objects in the calibration trajectory file. A movement threshold was set for each subject using the method of Shoji (2016). Output for each trait was recorded for every minute of the test to observe temporal patterns during the test.

The center of the open field was defined as a circle with diameter half the length of a side $(29 \mathrm{~cm})$. Distance traveled was the sum of all positional changes above the movement threshold in the combined trajectory file.

Times spent past three different thresholds in the light chamber were recorded: (1) 0.5 in. $(1.27 \mathrm{~cm})$ from the dark chamber, (2) midpoint of the light chamber, and (3) $0.5 \mathrm{in}$. $(1.27 \mathrm{~cm})$ from the edge of the wall of the light chamber.

For the predator cue test, entrance into each arm was recorded once a mouse was $12 \mathrm{in}$. $(30.48 \mathrm{~cm})$ from the end of the arm. Distance traveled was computed as the sum of all positional changes above the movement threshold in the combined trajectory file. 


\section{Corticosterone quantification}

Immediately following the predator cue test, each mouse was anesthetized using an isoflurane-soaked gauze and transferred to a glass jar. Once unresponsive, the mouse was decapitated, and blood was collected and stored on ice until all tests for the day were completed. Blood was centrifuged at $1200 \mathrm{rpm}$ for 10 min at $4{ }^{\circ} \mathrm{C}$ to collect plasma. Samples were stored at $-80^{\circ} \mathrm{C}$ until assay submission. Plasma corticosterone concentration was quantified by ELISA at the Wisconsin National Primate Research Center.

\section{Statistical analyses}

All statistical analyses were conducted in $\mathrm{R}$ ( $\mathrm{v}$ 3.4.1) ( $\mathrm{R}$ Development Core Team 2017). Linear models were built separately for each behavior using the $1 \mathrm{~m}$ function \{stats\}. Behaviors were treated as dependent variables. Strain, sex, age (for the open field test), and cross direction (for F1s) were treated as fixed, independent variables. Interactions suggested by graphical patterns were also evaluated. The significance of an independent variable was evaluated using additional sumof-squares tests comparing models that included or excluded the variable. Behaviors in F1s and parental strains were compared using $t$-tests. F1s from mothers of different strains were tested separately when the cross direction term in the linear model was significant. F1s were inferred to be similar to a parental strain when they were statistically indistinguishable from that strain but distinct from the other parental strain. F1s were inferred to be similar to the mid-parent value, defined as the arithmetic average of the parental means, when they were indistinguishable from that value but distinct from both parental strains. When F1s were statistically distinct from both parental distributions and the mid-parent value, they were inferred to be similar to midpoint values between the midparent value and the parental mean to which they were closest.

\section{Data availability}

All computational scripts used in video analysis are available in Supplementary Files. Raw measurements and associated metadata for each mouse are included in Supplementary Table 1.

\section{Results}

\section{Open field test}

We conducted open field tests at two life stages (juvenile and adult) to investigate how GI mice and mainland mice explore a brightly lit, open environment with high exposure. We observed extensive behavioral differences between GI mice and mainland mice at both juvenile and adult ages (Fig. 2; Table 1). Overall, GI mice spend more time in the center of the arena (Fig. 2a; Table 1), travel more (Fig. 2b; Table 1), and deposit fewer fecal boli than mainland mice (Table 1). Strain differences for time spent in the center of the arena and the number of fecal boli deposited are similar between ages. Alternatively, distance traveled shows a strong strain-by-age interaction, with the disparity between strains expanding after puberty.

F1 offspring from crosses between GI mice and mainland mice show behavioral patterns consistent with a nonadditive genetic architecture with occasional parental effects. For most behaviors, F1 averages are closer to the mainland strain (Fig. 2; Table 2). Only the number of fecal boli deposited by F1 adults is statistically indistinguishable from the mid-parent value (Table 2). Cross direction influences distance traveled in both juveniles and adults. F1s with a GI mother travel less than F1s with a mainland mother (Supplementary Table 2).

Collectively, these results indicate that GI mice evolved an increased willingness to explore novel, risky environments. Whereas boldness-related behaviors are consistent across life stages and cross directions, distance traveled in the open field is influenced by age and parental effects.

\section{Light/dark test}

To understand how exploration of a novel environment changes when a sheltered area is available, we conducted a light/dark test using a place preference chamber with equally sized light and dark chambers. We found that GI mice spend nearly twice as much time in the light chamber as mainland mice (Fig. 3a; Table 1). GI mice also enter the light chamber nearly twice as many times (Fig. 3b; Table 1). Strain differences are maintained when considering only exploratory bouts past the center of the light chamber (Fig. 3c-d; Table 1). As with the open field test, GI mice deposited less fecal boli, suggesting that baseline anxiety is similar in the two tests (Table 1). These patterns indicate that GI mice evolved increased willingness to leave sheltered areas and to venture farther from shelters compared to mainland mice.

\section{Predator Cue test}

To reveal how exploration is impacted by the presence of a predator cue, we conducted tests in a y-maze with one arm containing a cotton ball soaked in fox urine. In the first $10 \mathrm{~min}$ of the test with no cues present, both strains show a slight preference for the blank arm where no cue would be placed (Fig. 4a). This pattern could reflect the slight shading of this arm due to lighting constraints in the room. GI mice travel farther overall than mainland mice during these first $10 \mathrm{~min}$, echoing results from the open field test (Table 1). After both cues are presented, GI mice and mainland mice spend less 
a

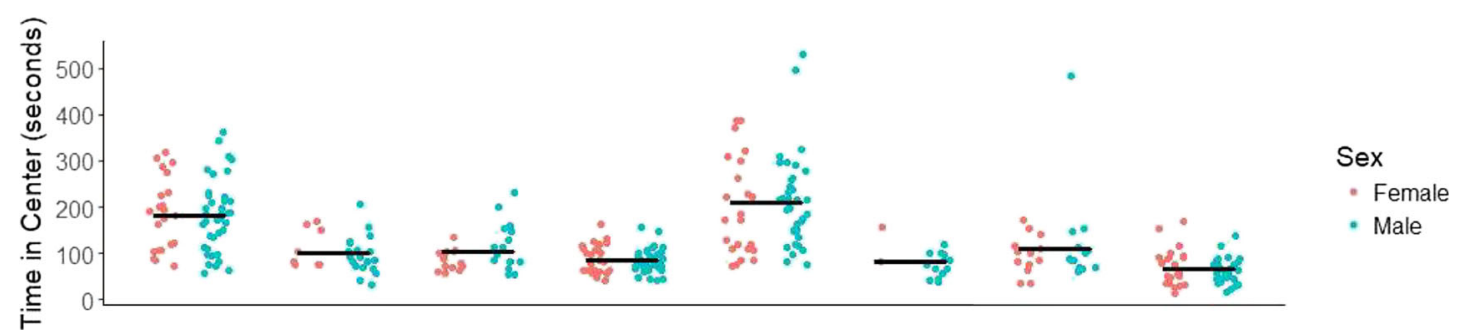

b

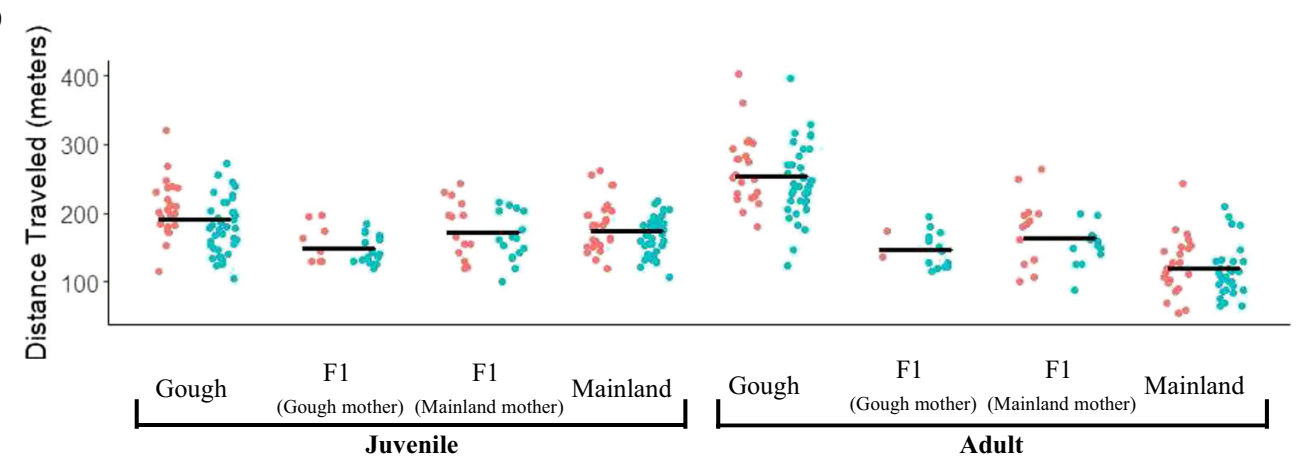

Fig. 2 Open field comparisons between strain and ages. Means across sexes are designated by horizontal black bars. F1s are separated based on strain of the mother. a Time spent in the center of the open field. b Distance traveled in meters

time in the arm containing the fox urine than in the arm containing the deer urine (Fig. 4a; Table 1). We find no evidence for strain differences in this avoidance of the predator cue.

Plasma corticosterone concentrations collected immediately following the predator cue test do not differ between strains (Fig. $4 \mathrm{~b}, t$-test; $P=0.447$ ). This result indicates that GI mice are as physiologically stressed as mainland mice by the presence of a predator cue though they continue to deposit fewer fecal boli $(t$-test; $P<0.001)$. Despite the apparent similarity in anxiety among the two strains, GI mice travel more than mainland mice after cues are presented (Table 1). These findings suggest that GI mice retain avoidance and stress responses associated with exposure to threats from terrestrial predators even while evolving a greater willingness to explore.

\section{Discussion}

Gough Island mice are more exploratory and less fearful than their mainland counterparts in novel, open environments without cues from terrestrial predators. Data from across our experiments demonstrate that GI mice show constant motion throughout each test with little preference for location except when direct cues of terrestrial predators are present. In contrast, mainland mice have high innate anxiety and prefer to remain in regions of each arena characteristic of fearful mice in commonly used behavioral assays (e.g., periphery of the open field, dark chamber of the light/dark box). Since all mice in this study were raised in a common setting, these behavioral differences among inbred strains have a genetic basis.
Although understanding which aspects of the environment on Gough Island stimulated behavioral evolution will require ecological studies, characteristics of GI mice and the island suggest potential causes. GI mice are the largest wild house mice in the world (Gray et al. 2015), offering an extreme case of the gigantism commonly observed among island rodents (Foster 1964; Adler and Levins 1994). Larger bodies demand greater energetic requirements, particularly during winter (Peters 1983). The willingness of GI mice to explore could have been driven by expanded caloric demand, especially with a diet that is highly varied and likely opportunistic (Jones et al. 2003; Cuthbert et al. 2016). Additionally, the evolution of boldness may have facilitated the transition to eating seabird chicks, which are a rich source of nutrients during winter when food is scarce and mortality is high (Cuthbert et al. 2016). In contrast to mice inhabiting typical mainland environments, less anxious mice on Gough Island can forage in open areas without danger from predators. For these reasons, exploration and boldness likely provide significant advantages to mice on Gough Island.

Comparisons across juvenile and adult life stages suggest that enhanced exploration and reduced anxiety have evolved along distinct developmental trajectories in GI mice. Although both juvenile and adult GI mice spend more time in the center of an open field and deposit fewer fecal boli, GI mice travel farther than mainland mice only after puberty. Results from other studies support the idea that exploration and boldness can be uncoupled. Pumpkinseed fish approach a novel food source and a potential threat differently (Coleman and Wilson 1998). Wild-caught starlings show greater escape motivation 


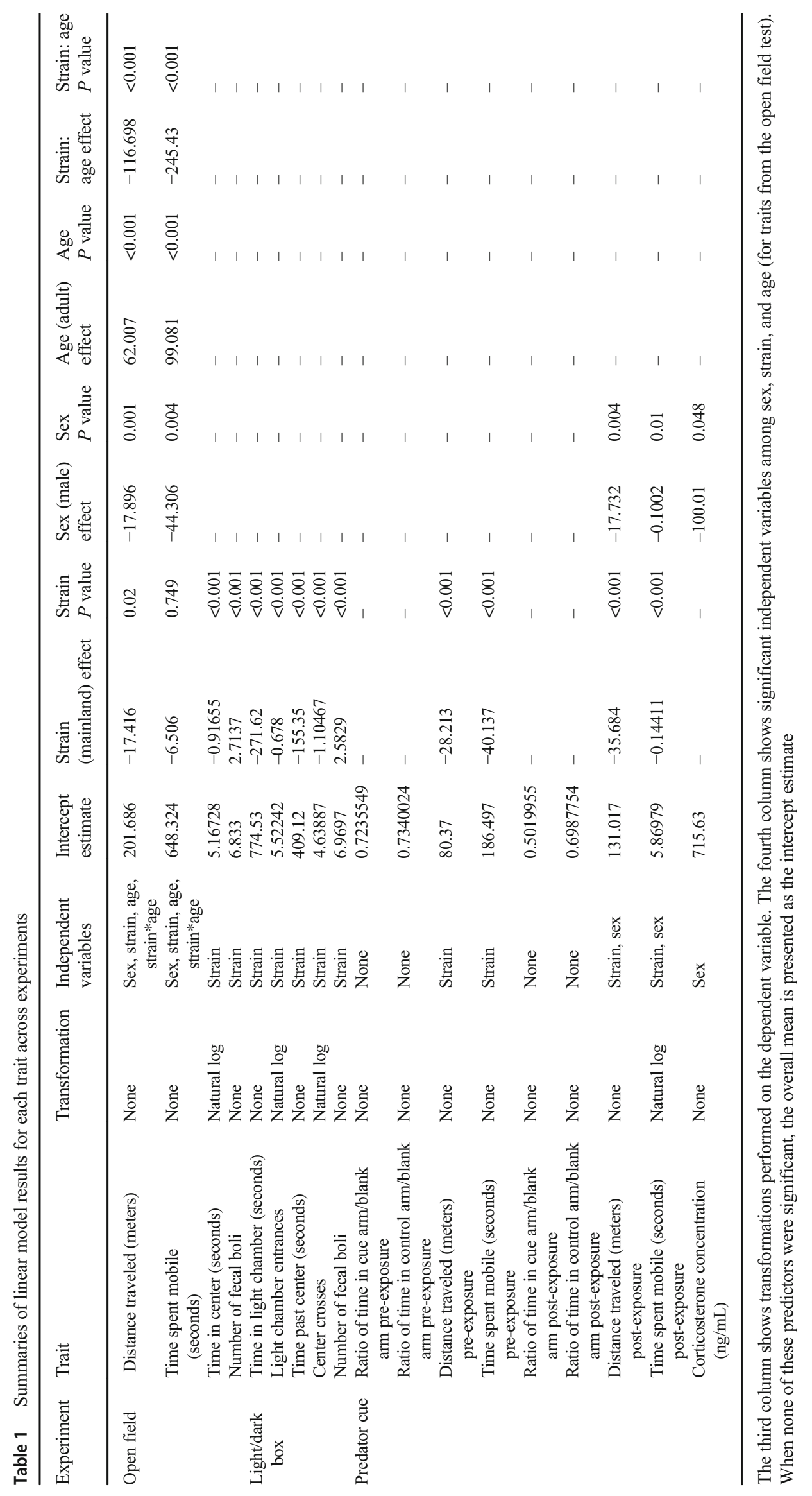


Table 2 Summary of effects influencing behaviors in the open field

\begin{tabular}{lllll}
\hline Experiment & Trait & Sex effect & Cross direction effect & F1 grouping \\
\hline Open field juvenile & Distance traveled & + & + & Underdominant (GI mother), Mainland (mainland mother) \\
& Time in center & - & - & Midparent/mainland midpoint \\
& Number of fecal boli & - & - & Gough Island \\
Open field adult & Distance traveled & + & + & Midparent/mainland midpoint \\
& Time in center & - & - & Midparent/mainland midpoint \\
& Number of fecal boli & - & - & Midparent \\
\hline
\end{tabular}

A "+" indicates significance of that variable for the given trait. F1 groupings are based on which values (mainland mean, GI mean, or midparent) the F1 distribution is significantly different from using a $t$-test. For traits with a significant cross direction effect, the two groups were treated separately

than hand-reared starlings when placed in a new cage, but the two groups of birds respond similarly to novel objects (Feenders et al. 2011). Organisms living in a complex environment are expected to benefit from context-specific evolution of behavior (Coleman and Wilson 1998; Sih et al. 2004). Exploration, which is tied to the need for resources, including food and shelter, takes on greater importance when mice leave the nest and care of their mother. Alternatively, reducing unnecessary anxiety may increase both juvenile and adult fitness by reducing negative health consequences from continuous stress (Koolhaas et al. 1999; Elliot et al. 2017). Therefore, natural selection could uncouple the developmental timing of exploration and anxiety.

Rodents living on islands without terrestrial predators are expected to lose the avoidance response to predator cues (Orrock 2010). It is interesting, therefore, that GI mice and mainland mice respond similarly to fox urine. There are multiple explanations for this finding; none of which is mutually exclusive. First, GI mice may not have been on the island long enough for new genetic variants that relax the response to predator cues to arise and spread. Perhaps this phenotype has a smaller mutational target size than general anxiety, a trait for which we observed a heritable reduction in GI mice. A second possibility is that selection on general anxiety may be more direct than selection to remove predator cue responses. The presence or absence of a predator cue response makes no difference when predators are absent, whereas reducing general anxiety can facilitate the optimization of foraging strategies and reduce energy expenditure from unnecessary stress (Elliot et al. 2017). A final explanation is that the pathway for detecting terrestrial predators could play additional functional roles in GI mice. Sulfur-containing byproducts of meat-eating vertebrates are known to be aversive stimuli for rodents (Nolte et al. 1994), but there may be other sulfur-containing

\section{a}

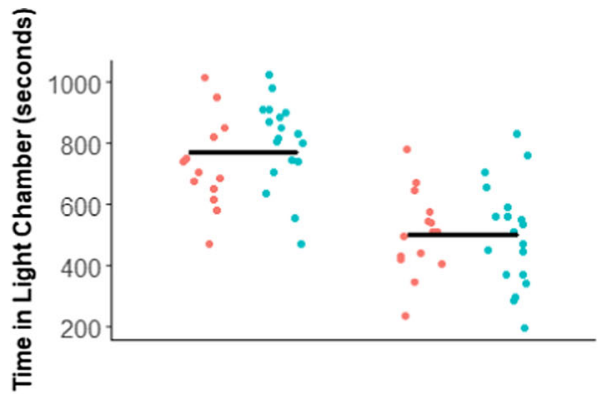

C

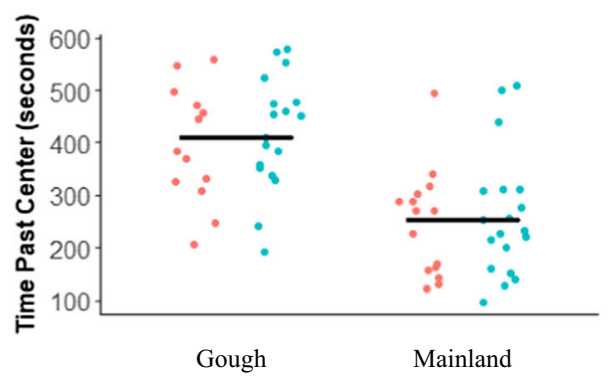

Fig. 3 Results from light/dark test. Means across sexes are designated by horizontal black bars. a Amount of time spent in light chamber of light/ dark box. b Number of entrances to the light chamber. c Amount of time b

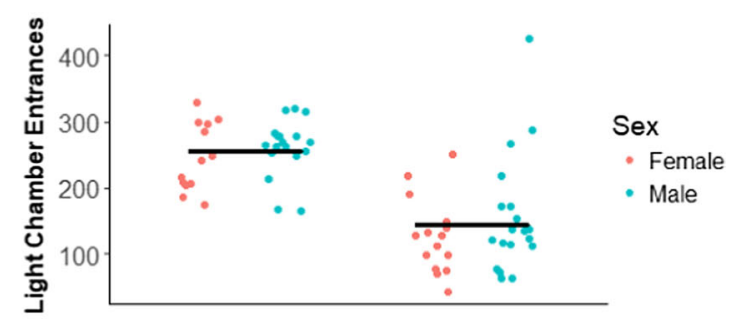

d

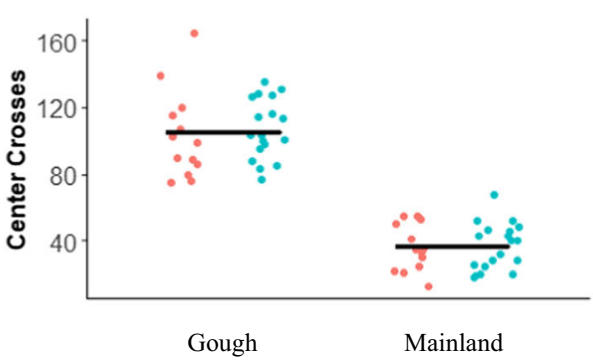

spent past the center of the light chamber. $\mathbf{d}$ Number of crosses past the center of the light chamber 
Fig. 4 Results from predator cue test. a Mean ratio and standard error of time spent in arm with a given cue to time spent in blank arm. Ratios on the left are for the $10 \mathrm{~min}$ of exploration before cues were added. b Corticosterone concentration of mice immediately after the predator cue test. Means across sexes are designated by horizontal bars. Note the assay has a maximum detection limit of $1000 \mathrm{ng} / \mathrm{mL}$

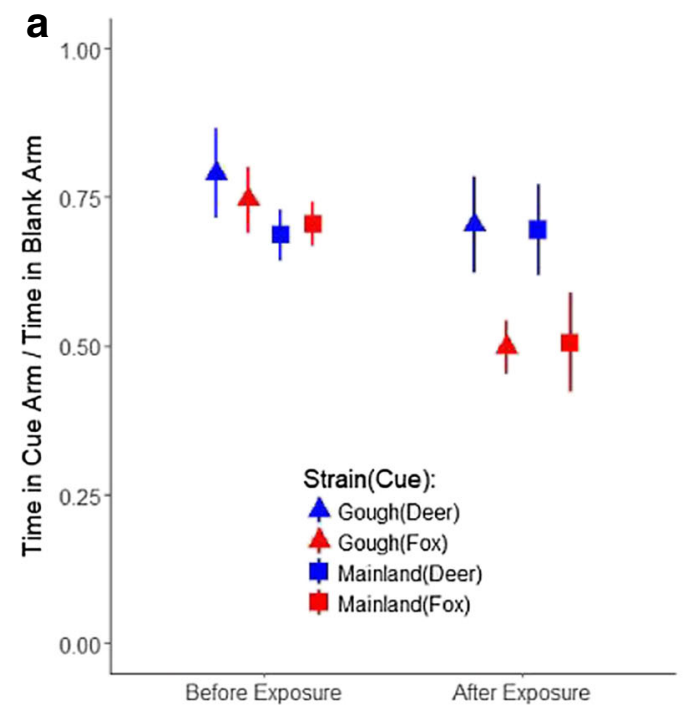

compounds on Gough Island that mice need to detect. Since fish-eating seabirds are a major source of nutrition for GI mice during the winter season (Cuthbert et al. 2016; Caravaggi et al. 2019), the ability to locate nests emitting sulfur signals could be beneficial.

It is worth noting that GI mice continue to deposit fewer fecal boli after exposure to predator urine, despite showing similar corticosterone levels to mainland mice following the test. While the number of fecal boli deposited during a behavioral test is a commonly used proxy for anxiety (Flint et al. 1995), it is likely influenced by additional factors (e.g., metabolism) and may detect different aspects of anxiety than corticosterone. It is also possible that the method of anesthesia and euthanasia we used prior to plasma collection caused similar levels of anxiety in both mouse strains, whereas fecal boli counts represent stress levels during the test itself. Additional measurements of corticosterone concentration both before the predator cue exposure and in individuals that do not undergo behavioral testing will provide a better understanding of the dynamics of physiological stress in these strains.

The phenotypic patterns we documented in F1s provide insights into the genetic architecture that underlies the evolution of new behaviors in GI mice. We found that $\mathrm{F} 1 \mathrm{~s}$ resemble mainland mice more than GI mice in open field tests, implying that GI mouse alleles are recessive to mainland mouse alleles for several behaviors connected to boldness and exploration. Recessive mutations tend to reduce function (Simmons and Crow 1977), suggesting that the variants of interest could have decreased the expression of genes or pathways that are typically active in mainland mice. The evolutionary trajectory of recessive mutations in GI mice would have depended on their initial frequencies. Whereas new recessive variants would have required stronger selection to become established and spread to high frequency than new dominant variants (Haldane 1927), the probability of fixation of standing variants that contribute to adaptation is independent of dominance (Orr and Betancourt 2001). The inference of recessive gene action also raises the prospect that behavioral evolution was accomplished through a small number of mutations with large phenotypic effects. Although loci that affect behavior in laboratory strains of mice have been mapped to every chromosome (Flint 2003), alleles with substantial effects exist for some behaviors, including boldness and exploration (Cohen et al. 2001; Parker et al. 2013).

Our characterization of F1s uncovered additional factors that shape behavior in GI mice. An apparent maternal effect on distance traveled in the open field acts in the opposite direction of the strain effect (i.e., GI mouse mothers reduce distance traveled by F1 offspring). This result implies that the genetic increase in distance traveled in GI mice is greater than it appears based on comparisons to mainland mice since this maternal effect must be overcome. Antagonism between maternal and direct genetic effects provides a barrier to selection and could draw populations away from optimal trait values, depending on the degree of covariance between these effects (Cheverud and Moore 1994).

Several caveats accompany our interpretations. The mainland strain we profiled was chosen based on its availability and common usage in mouse genetics. If the behavior of this wild-derived inbred strain departs significantly from the mainland mice from which GI mice are descended, our conclusions about the evolution of new behaviors in GI mice could be incorrect. Western Europe is the most likely ancestral origin of M. m. domesticus in North America and on Gough Island (Gray et al. 2014). Detailed reconstruction of behavioral evolution in GI mice will ultimately require behavioral studies in specific source populations, which remain to be identified. Our study also assumes that the behavior in the laboratory is representative of the behavior in the wild. While the simplicity of our experimental design facilitates the identification of 
causal factors in behavioral differences, those interpretations are limited to the environment in which the tests were conducted. Mice in the wild experience complex environments without ad libitum access to food and exposed to many context-dependent signals of danger. Other studies have incorporated predator cues and alarm signals as part of the open field test to mimic these natural conditions (Sievert et al. 2020). Should these conditions have been present in our open field test, we may have obtained different results. Incorporating more realistic scenarios (e.g., fasting, outside enclosures) in future behavioral studies will help broaden our interpretations of the behavioral changes in GI mice.

Our study is among the first to report inherited differences in behavior between island and mainland populations (Brodin et al. 2013; Jolly et al. 2018). Island deer mice that evolved larger bodies are less aggressive than their mainland relatives, but this behavioral difference is not heritable (Baier and Hoekstra 2019). Perhaps the extreme ecological conditions on Gough Island (e.g., lack of predators, lack of human commensals, presence of seabird chicks as a source of food in winter) have created particularly strong selective pressure for behavioral evolution. Regardless of the environmental causes, our demonstration of heritable differences between island and mainland populations in a genetic model organism sets the stage for identifying genes responsible for behavioral evolution associated with island colonization. GI mice could also serve as a useful experimental model for exploration and anxiety in humans (Sokolowska and Hovatta 2013; Ashbrook et al. 2015) where the list of candidate genes for these behaviors continues to grow (Meier and Deckert 2019).

Supplementary Information The online version contains supplementary material available at https://doi.org/10.1007/s00265-021-03003-6.

Acknowledgements We thank Megan Latsch and Dr. Michelle Parmenter for conducting the pilot study that inspired this project. We thank two anonymous reviewers for helpful feedback on the manuscript. We thank Dr. Andrew Bakken for helping construct the open field and Dr. John Stratton for assistance in developing scripts.

Author contribution JAS helped design the study, carried out the behavioral testing, performed the video analysis, conducted the statistical testing, and drafted the manuscript; MJN conceived of the study, helped design the study, and critically revised the manuscript; BAP helped design the study and critically revised the manuscript. All authors gave final approval for publication and agree to be held accountable for the work performed therein.

Funding This research was funded by National Institutes of Health $(\mathrm{NIH})$ grant R01 GM100426. JAS was partially supported by the NIH Graduate Training Grant in Genetics at the University of Wisconsin - Madison (T32 GM007133). MJN was partially supported by an NHGRI training grant (5T32HG002760) to the UW-Madison Genomic Sciences Training Program.

\section{Declarations}

Ethics approval Guidelines applicable to the use of animals and all experiments were approved by the Institutional Animal Care and Use Committee at the University of Wisconsin-Madison (protocol no. V005209).

Competing interests The authors declare no competing interests.

Open Access This article is licensed under a Creative Commons Attribution 4.0 International License, which permits use, sharing, adaptation, distribution and reproduction in any medium or format, as long as you give appropriate credit to the original author(s) and the source, provide a link to the Creative Commons licence, and indicate if changes were made. The images or other third party material in this article are included in the article's Creative Commons licence, unless indicated otherwise in a credit line to the material. If material is not included in the article's Creative Commons licence and your intended use is not permitted by statutory regulation or exceeds the permitted use, you will need to obtain permission directly from the copyright holder. To view a copy of this licence, visit http://creativecommons.org/licenses/by/4.0/.

\section{References}

Adler GH, Levins R (1994) The island syndrome in rodent populations. Q Rev Biol 69:473-490

Ashbrook DG, Williams RW, Lu L, Hager R (2015) A cross-species genetic analysis identifies candidate genes for mouse anxiety and human bipolar disorder. Front Behav Neurosci 9:171

Baier F, Hoekstra HE (2019) The genetics of morphological and behavioural island traits in deer mice. Proc R Soc B 286:20191697

Berry RJ (1992) The significance of island biotas. Biol J Linn Soc 46:312

Blumstein DT, Daniel JC (2005) The loss of anti-predator behaviour following isolation on islands. Proc R Soc Lond B 272:1663-1668

Brodin T, Lind MI, Wiberg MK, Johansson F (2013) Personality trait differences between mainland and island populations in the common frog (Rana temporaria). Behav Ecol Sociobiol 67:135-143

Brown JS, Kotler BP (2004) Hazardous duty pay and the foraging cost of predation. Ecol Lett 7:999-1014

Caligioni C (2009) Assessing reproductive status/stages in mice. Curr Protoc Neurosci 48:A.4I.1-A.4I.8

Caravaggi A, Cuthbert RJ, Ryan PG, Cooper J, Bond AL (2019) The impacts of introduced House Mice on the breeding success of nesting seabirds on Gough Island. Ibis 161:648-661

Cheverud JM, Moore AJ (1994) Quantitative genetics and the role of environment provided by relatives in behavioral evolution. In: Boake CRB (ed) Quantitative Genetic Studies of Behavioral Evolution. University of Chicago Press, Chicago, pp 67-100

Cohen RM, Kang A, Gulick C (2001) Quantitative trait loci affecting the behavior of $\mathrm{A} / \mathrm{J}$ and $\mathrm{CBA} / \mathrm{J}$ intercross mice in the elevated plus maze. Mamm Genome 12:501-507

Coleman K, Wilson DS (1998) Shyness and boldness in pumpkinseed sunfish: individual differences are context-specific. Anim Behav 56: 927-936

Cooper WE, Pyron RA, Garland T (2014) Island tameness: living on islands reduces flight initiation distance. Proc R Soc B 281: 20133019

Creel S, Christianson D (2008) Relationships between direct predation and risk effects. Trends Ecol Evol 23:194-201

Cuthbert RJ, Wanless RM, Angel A, Burle M-H, Hilton GM, Louw H, Visser P, Wilson JW, Ryan PG (2016) Drivers of predatory behavior 
and extreme size in house mice Mus musculus on Gough Island. J Mammal 97:533-544

Darwin C (1840) Journal of Researches Into the Geology and Natural History of the Various Countries Visited by H.M.S. Beagle, Under the Command of Captain Fitzroy from 1832 to 1836 by Charles Darwin. Colburn, London

Dmitriew CM (2011) The evolution of growth trajectories: what limits growth rate? Biol Rev 86:97-116

Elliott KH, Norris DR, Betini GS, Dworkin I (2017) Scared fitless: context-dependent response of fear to loss of predators over evolutionary time in Drosophila melanogaster. FACETS 2:342-354

Feenders G, Klaus K, Bateson M (2011) Fear and exploration in European starlings (Sturnus vulgaris): a comparison of handreared and wild-caught birds. PLoS ONE 6:e19074

Flint J (2003) Analysis of quantitative trait loci that influence animal behavior. J Neurobiol 54:46-77

Flint J, Corley R, DeFries JC, Fulker DW, Gray JA, Miller S, Collins AC (1995) A simple genetic basis for a complex psychological trait in laboratory mice. Science 269:1432-1435

Foster JB (1964) Evolution of mammals on islands. Nature 202:234-235

Grant PR (1998) Evolution on Islands. Oxford University Press, Oxford

Grant PR (1999) Ecology and Evolution of Darwin's Finches. Princeton University Press, Princeton

Gray MM, Wegmann D, Haasl RJ, White MA, Gabriel SI, Searle JB, Cuthbert RJ, Ryan PG, Payseur BA (2014) Demographic history of a recent invasion of house mice on the isolated Island of Gough. Mol Ecol 23:1923-1939

Gray MM, Parmenter MD, Hogan CA, Ford I, Cuthbert RJ, Ryan PG, Broman KW, Payseur BA (2015) Genetics of rapid and extreme size evolution in island mice. Genetics 201:213-228

Haldane JBS (1927) A mathematical theory of natural and artificial selection, Part V: selection and mutation. Math Proc Cambridge 23: $838-844$

Hall CS (1934) Emotional behavior in the rat I Defecation and urination as measures of individual differences in emotionality. J Comp Psychol 18:385-403

Halpin ZT (1981) Adult-young interactions in island and mainland populations of the deermouse Peromyscus maniculatus. Oecologia 51: 419-425

Horii Y, Nagasawa T, Sakakibara H et al (2017) Hierarchy in the home cage affects behaviour and gene expression in group-housed C57BL/6 male mice. Sci Rep 7:6991

Jolly CJ, Webb JK, Phillips BL (2018) The perils of paradise: an endangered species conserved on an island loses antipredator behaviours within 13 generations. Biol Lett 14:20180222

Jones AG, Chown SL, Gaston KJ (2003) Introduced house mice as a conservation concern on Gough Island. Biodivers Conserv 12: 2107-2119

Koolhaas JM, Korte SM, de Boer SF, van der Vegt BJ, van Reenen CG, Hopster H, de Jong IC, Ruis MAW, Blokhuis HJ (1999) Coping styles in animals: current status in behavior and stress-physiology. Neurosci Biobehav Rev 23:925-935

Losos JB, Ricklefs RE (2009) Adaptation and diversification on islands. Nature 457:830-836
Meier SM, Deckert J (2019) Genetics of anxiety disorders. Curr Psychiatr Rep 21:16

Nolte DL, Mason JR, Epple G, Aronov E, Campbell DL (1994) Why are predator urines aversive to prey? J Chem Ecol 20:1505-1516

Orr HA, Betancourt AJ (2001) Haldane's sieve and adaptation from the standing genetic variation. Genetics 157:875-884

Orrock JL (2010) When the ghost of predation has passed: do rodents from islands with and without fox predators exhibit aversion to fox cues? Ethology 116:338-345

Parker CC, Sokoloff G, Leung E, Kirkpatrick SL, Palmer AA (2013) A large QTL for fear and anxiety mapped using an F2 cross can be dissected into multiple smaller QTLs. Genes Brain Behav 12:714 722

Parmenter MD, Gray MM, Hogan CA, Ford IN, Broman KW, Vinyard CJ, Payseur BA (2016) Genetics of skeletal evolution in unusually large mice from Gough Island. Genetics 204:1559-1572

Peters RH (1983) The Ecological Implications of Body Size. Cambridge University Press, Cambridge

Phifer-Rixey M, Nachman MW (2015) Insights into mammalian biology from the wild house mouse Mus musculus. ELife 4:e05959

Phifer-Rixey M, Bi K, Ferris KG, Sheehan MJ, Lin D, Mack KL, Keeble SM, Suzuki TA, Good JM, Nachman MW (2018) The genomic basis of environmental adaptation in house mice. PLoS Genet 14: e1007672

R Development Core Team (2017) R: A language and environment for statistical computing. R Foundation for Statistical Computing, Vienna, Austria, http://www.R-project.org

Rowe-Rowe DT, Crafford JE (1992) Density, body size, and reproduction of feral house mice on Gough Island. S Afr J Zool 27:1-5

Samson AL, Ju L, Ah Kim H, Zhang SR, Lee JAA, Sturgeon SA, Sobey CG, Jackson SP, Schoenwaelder SM (2015) MouseMove: an open source program for semi-automated analysis of movement and cognitive testing in rodents. Sci Rep 5:16171

Shoji H (2016) Scaling law in free walking of mice in circular open fields of various diameters. J Biol Phys 42:259-270

Sievert T, Kerkhoven A, Haapakoski M, Matson KD, Ylönen O, Ylönen $\mathrm{H}$ (2020) In utero behavioral imprinting to predation risk in pups of the bank vole. Behav Ecol Sociobiol 74:13

Sih A, Bell A, Johnson JC (2004) Behavioral syndromes: an ecological and evolutionary overview. Trends Ecol Evol 19:372-378

Simmons MJ, Crow JF (1977) Mutations affecting fitness in Drosophila populations. Annu Rev Genet 11:49-78

Sokolowska E, Hovatta I (2013) Anxiety genetics - findings from crossspecies genome-wide approaches. Biol Mood Anxiety Disord 3:9

Verrill GE (1895) Notes on birds and eggs from the islands of Gough, Kerguelen, and South Georgia. Trans Connecticut Acad Arts Sci 11: 429-480

Wace NM (1961) The vegetation of Gough Island. Ecol Monogr 31:337367

Williamson MH (1981) Island Populations. Oxford University Press, Oxford

Publisher's note Springer Nature remains neutral with regard to jurisdictional claims in published maps and institutional affiliations. 